\title{
DIFFERENT SHADES OF GREEN: A COMPARATIVE STUDY ON NATURE RELATEDNESS AND ECOLOGICAL CONSCIOUSNESS AMONG SOUTH KOREAN, SWISS, AND CZECH STUDENTS
}

\author{
Barthelmess, P. Y., Schüz, M., Fuchs, R., Kučera, D., Prandini, M.
}

How concerned are today's students about environmental issues? Do they sense urgency for change towards a more environmentally compatible life? Who should act and what impact does one's individual action have? And last but not least, do ecological consciousness and action go together with a sense of nature relatedness? More than 1,600 South Korean, Swiss, and Czech students have participated in this comparative survey. Nearly all of them affirm that ecological considerations influence their daily behavior. Most of them see the main agent of change in themselves; the impact of one's individual action, however, is seen differently along the East and West cultural divide. Also when it comes to one's personal sense of closeness to nature, we can observe an East West cultural variation. On average, the South Koreans reveal a greater closeness towards nature than Swiss and Czech students, this despite the fact that they have the largest percentage in urban background, and consequently reveal the least physical familiarity with the natural world. In our effort to interpret these results, we have included a discussion about the diverging cultural background of the three sample groups. While they all agree on the urgency of the issue and the necessity of more pro-environmental change, depending on their culture, their ideas about the right means to introduce a change in behavior differ.

JEL Classification: J17, M14, Q56, Z12-13

Keywords: naturerelatedness; ecologic consciousness; intercultural study; corporate ecologic responsibility, sustainable corporate responsibility

\section{Introduction}

Looking at mankind's evolutionary history, Wilson (1984) argues that humans possess an innate need to affiliate with nature - a need based on the insight that nature has assured mankind's continued survival as a species. Wilson's "biophilia hypothesis" (Kellert and Wilson, 1993) appears to be proven by the fact that all over the world most people value nature highly and are willing to spend time and money in order to interact and enjoy nature (Dunlap and VanLiere, 1978; Dunlap, Van Liere, Mertig, and Jones, 2000; Clayton, 2003; Nisbet and Zelenski, 2011).

However, this cognitive insight about nature's value and our dependence on it does not necessarily translate into environmentally responsible action (Dunlap, Van Liere, Mertig, and Jones, 2000; Kaplan, 2000; Kortenkamp and Moore, 2001; Pooley and O'Connor, 2000). In the last few decades, our species has caused earth's environmental decline at an unprecedented scale, speed, and depth. Today, most countries, and the world as a whole, are running ecological deficits - this due to our increasingly unsustainable way of living. How can we explain the fact that in the face of increasing environmental problems, we still continue to live the very lifestyles that damages our life source?

Various research has been conducted to examine and understand the discrepancy between cognitive insight about nature's value and environmentally responsible behavior (Allen and Ferrand, 1999; Dunlap, and Mertig, 1995; Kaiser, Wölfing, and Fuhrer, 1999; Nordlund and Garvill, 2002; Pelletier, Dion, Tuson, and GreenDemers, 1999, Dutcher, Finley, Luloff, and Buttolph Johnson, 2007; Frantz and Mayer, 2009). The focal point has become the question of humans' sense of connectedness to nature (Allen and Ferrand, 1999; Clayton, 2003; Iwata, 2001; Mayer and Frantz, 2004; Pooley and 
O'Connor, 2000). The hypothesis is that environmental concerns relate directly to the degree with which individuals see themselves as part of the natural world: If one values and feels concern for nature, one will then behave in an environmentally responsible manner, and respectively the opposite, if one lives one's life disconnected from the natural world, one would care much less about one's impact on nature (Dunlap and VanLiere, 1978; Howard 1997; Dunlap, Van Liere, Mertig, and Jones, 2000; Clayton, 2003).

How connected do we feel with nature then? How, and respectively what, can we measure to make an assertion about one's connectedness with nature? Arne Naess (1973) has coined the term ecological identity or ecological self in order to describe the level of understanding of our interconnectedness with the earth and our sense of inclusion in nature. An ecological identity connects the self with nature as a whole so that damage to the planet is perceived as damage to the self (Conn 1998). In search of the ecological self, Clayton (2003) has investigated environmental self-concepts, and linking environmental self-definition with self-reports of environmental attitudes and behavior.

Beyond, respectively in addition to, the cognitive aspects, others such as Kals, Schumacher, and Montada (1999) have investigated the role of emotions and experiences and how these factors contribute to one's connectedness to nature. Allen and Ferrand (1999) closely examined issues such as one's personal biography (rural or urban upbringing), one's memories about positive past and present natural experiences, one's self-identification with nature, and one's emotional response to nature (also see: Clayton 2003, Mayer and Frantz 2004). In a more recent effort, Nisbet, Zelensky and Murphy (2009) have developed a Nature Relatedness Scale (NRS) which deducts the respondents' sense of interconnectedness with nature by integrating three aspects - affective, cognitive, and experience - into the measurement of one's relationship with nature.

In this study, we have tested the NRS in three different national settings - among students in South Korea, Switzerland, and the Czech Republic. Do they all share a similar scale of nature relatedness? Are there differences? In which way do they differ? Where do these differences stem from? And last but not least, what is culture's impact? The aim of this study is to test the NRS in a comparative way in different national settings in order to find out whether the scale is internationally applicable and how cultural differences come into play when measuring one's relatedness with nature.

\section{Study - Participants and Procedure}

This comparative study is based on an online survey which included 829 South Korean undergraduate and graduate students of Chungang, Hanyang, Sungkyungkwan, Korea, Soongsil, Kongju, Ajou, Sogang University and SolBridge International School of Business, 673 Swiss students of the Zurich University of Applied Sciences, and 147 Czech students of the University of Economics, Prague. The difference in number is due to the following two facts: the distribution of the survey as well as the motivation of the students to participate. Especially when it comes to the Swiss and South Korean students, the latter mentioned issue is paramount, since the distribution range has been more or less the same (app. 9'000). The lower interest on the Swiss side also shows itself in their answer pattern, which we will present below. On the Czech side, the survey has been less widely distributed. The participation rate, however, was even lower, which also indicates a lower level of interest for the matter as indicated below. The sample reveals a more or less even gender participation of $52 \%$ male and $48 \%$ female (South Korea), $42.6 \%$ male and $57.4 \%$ female (Switzerland), and $36.1 \%$ male and $63.9 \%$ female (Czech Republic). The age group of 20-26 included $93.4 \%$ of all South Koreans participating, $75.4 \%$ of all Swiss survey participants, and $87.8 \%$ of all Czech participants. As expected, on the issue of urban respectively rural background, the samples diverge: $89.5 \%$ of all South Korean survey participants have spent most of their lives in an urban environment. The Czech participants reveal also a relatively high level of urban background at $75.5 \%$; this contrasts to $34.5 \%$ of all Swiss survey participants.

This survey has been conducted anonymously in the form of an online survey. It posed eight questions - e.g. those about the level of concern over the present day condition of the planet and the importance of ecological considerations in the probands' all-day life activities as well as questions concerning one's affective, cognitive, and physical nature relatedness. For the latter, we have adopted Nisbet's, Zelensky's and Murphy's NRS-questionnaire (2009), which measures one's nature relatedness-Self - which represents "an internalized identification with nature, reflecting feelings and thoughts about one's personal connection to nature"; one's nature relatednessPerspective - which reflects "an external, nature-related worldview, a sense of agency concerning individual human actions and their impact on all living things"; and one's nature relatedness-Experience - which reflects "a physical familiarity with the natural world, the level of comfort with and desire to be out in nature". All three issues are supposed to be interconnected in the sense that 
positive experience goes together with positive feelings as well as with positive worldview.

The nature related scale of Nisbet, Zelensky, and Murphy (2009) has been developed on the basis of North American data. This study proves its applicability for the three different South Korean, Swiss, and Czech culture groups. The internal consistency test on the South Korean, Swiss, and Czech students' NRS shows an acceptable Cronbachs $\alpha$ (value 0.767 ) for the South
Korean, a good Cronbachs $\alpha$ for the Swiss (value 0.808), and an acceptable Cronbachs $\alpha$ for the Czech data (value 0.769). From a statistical perspective, this means that the nature-relatedness scores can be calculated and used for all three respondent groups.

The nominal data for all eight questions has been analyzed by Chi-square test and metrically scaled data by ANOVA. All results outlined in this article proved to be highly significant $(\mathrm{p} \geq 0.01)$.

\section{Survey Results}

\section{Do ecological conside-rations influence your behavior?}

Nearly all South Korean students $(90.5 \%)$ affirm that ecological considerations influence their daily behavior. In comparison to their Swiss and Czech counterparts, South Korean students include ecological considerations more often in their behavior ( $49.2 \%$ vs. $33 \%$ and $19 \%)$.

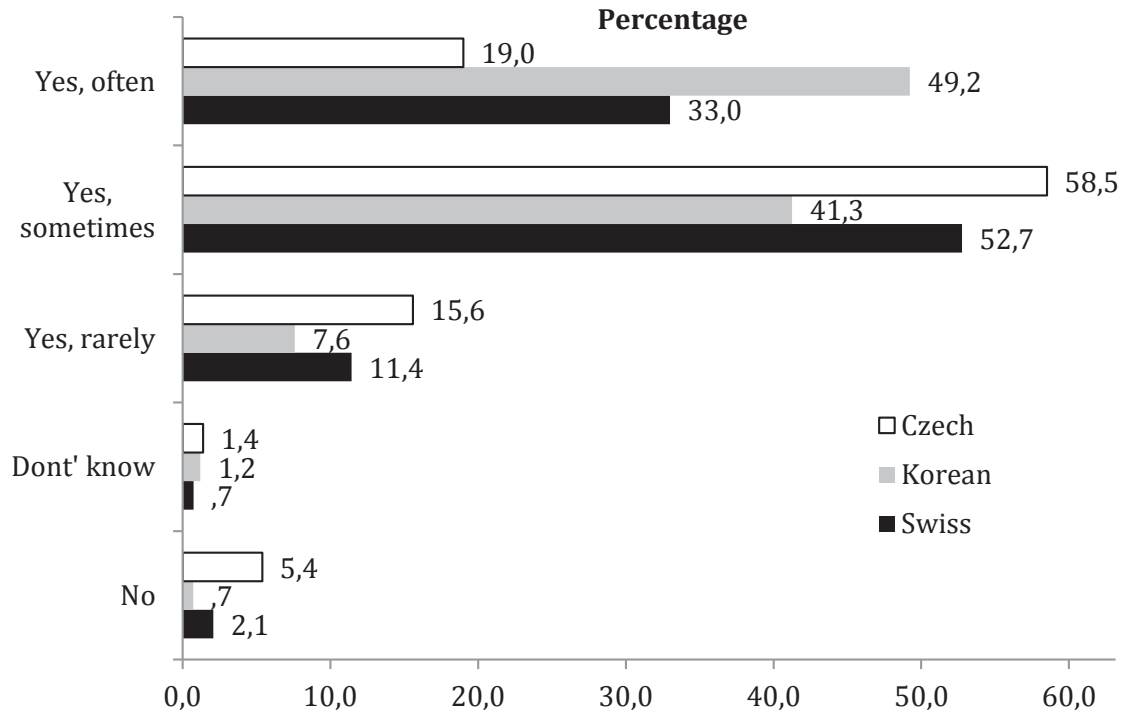

How do ecological considerations influence your behavior?

Interestingly South Korean, Swiss, and Czech students share a similar prioritization when it comes to ecologically driven behavior: Garbage disposal in the sense of collecting one's waste without outside pressure (I do not leave my waste in the mountains / on the beach / in the park) tops the list.

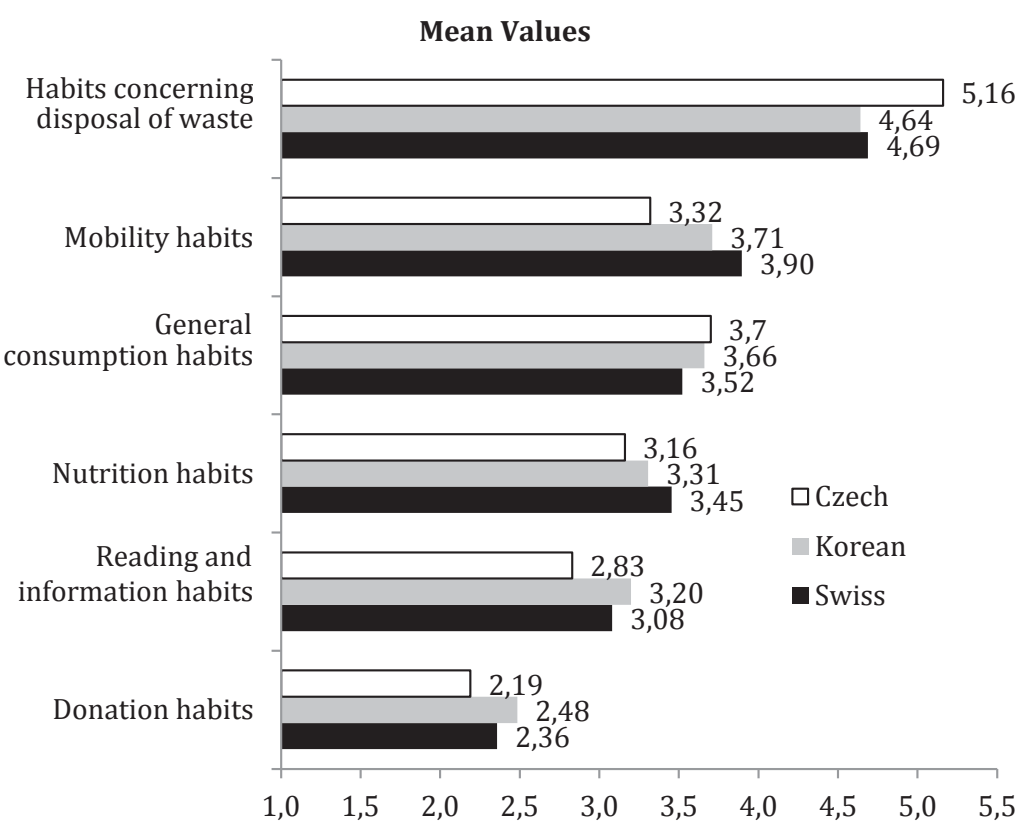


2. Imagine yourself in 10 years. How important are the following subject areas for you? From 1 to 4 rank them according to their importance for you. Note: *Answer option for the Swiss and Czech: I want to live in a country that provides social peace and economic prosperity.

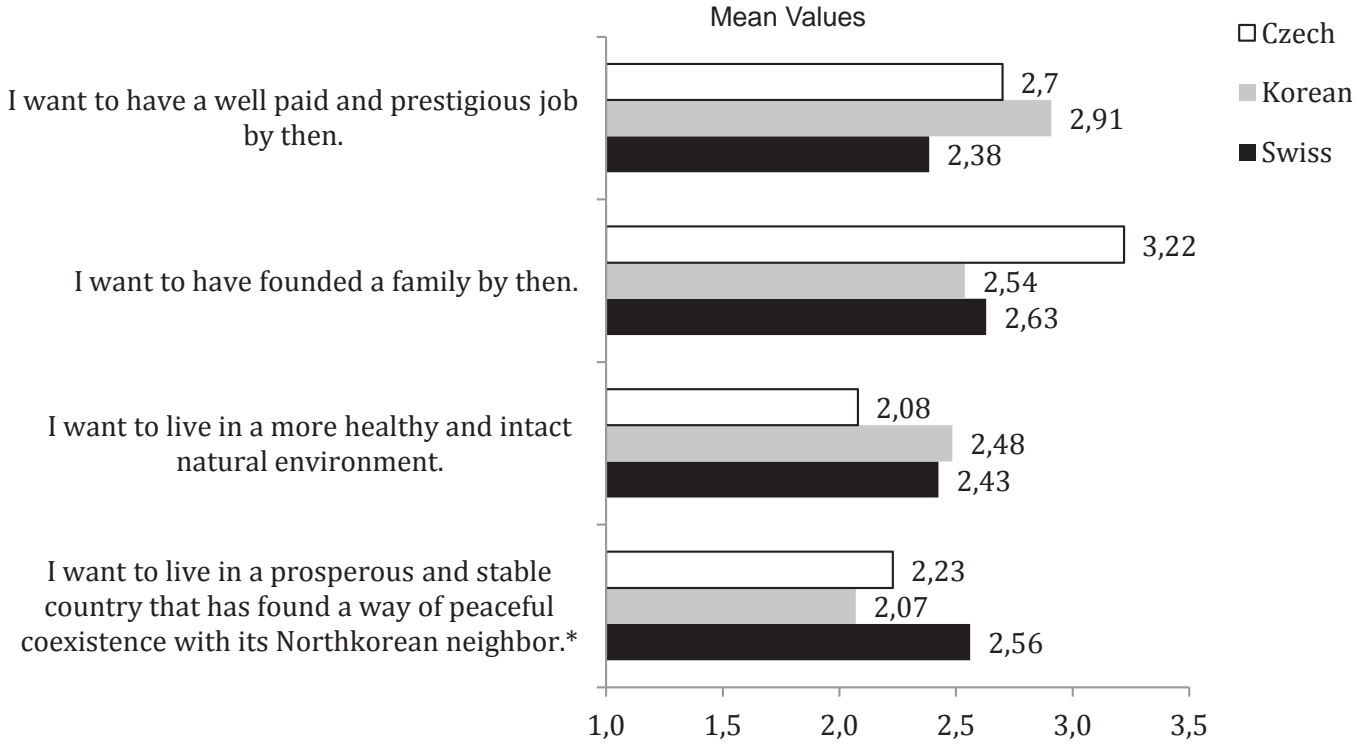

Of four possible options, South Koreans opted for a professional career as their number one priority, whereas the Swiss do not show any significant preference between the four options. Interestingly, the Czech students see family as a little more relevant than a professional career and significantly more relevant than a life in a healthy and intact natural environment or a life in peace. Despite their environmental concern, neither of them put this issue on the top of each one of their individual agendas.

\section{Regarding the future of our environment, mentioned in the two previous questions: Who should take action?}

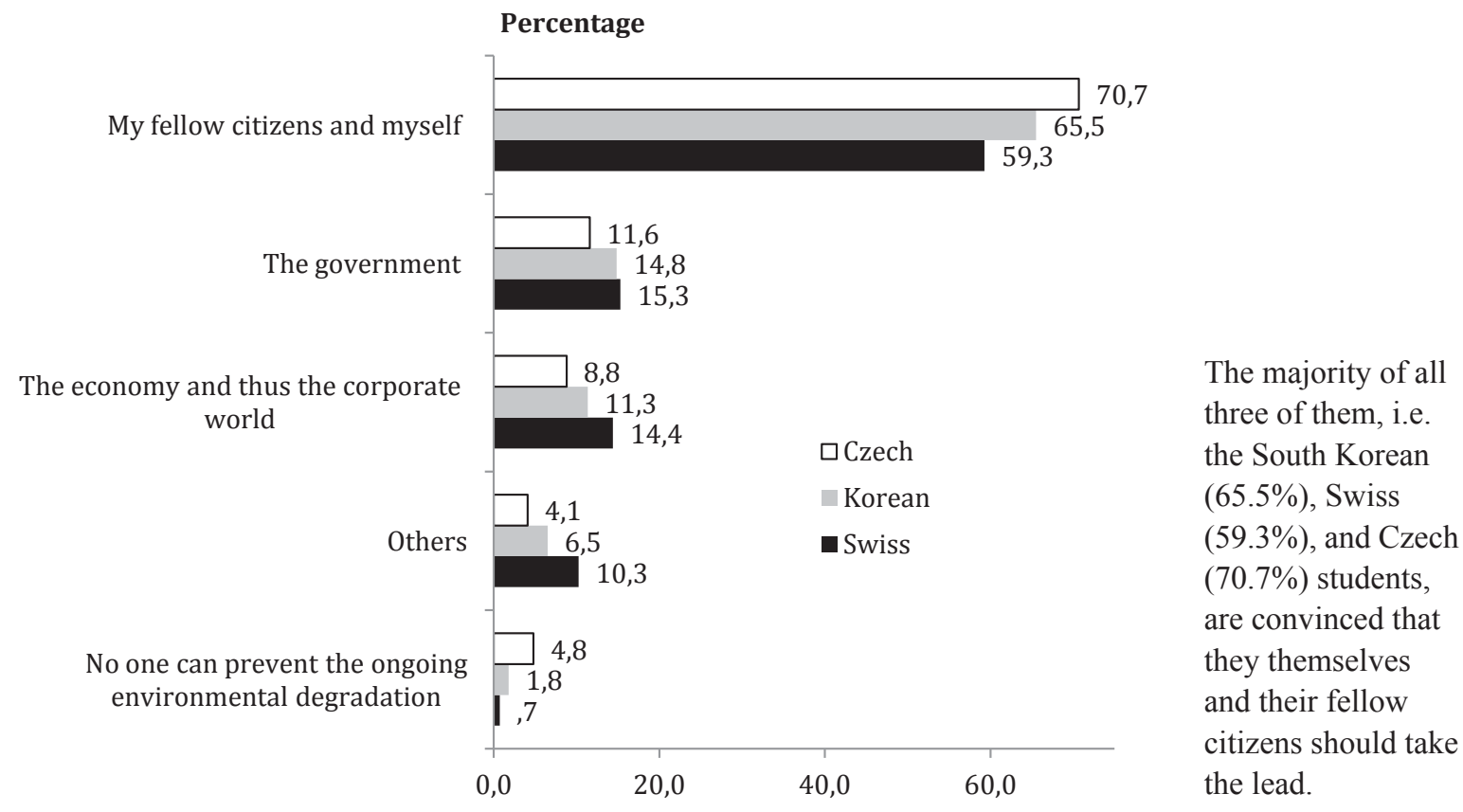


4. Will your personal environmentally compatible actions today have a significant impact on the condition of nature in the future?

On this issue, the difference between the sample groups is striking. Whereas $63.4 \%$ of all South Korean students consider the impact of their action as "strong" to "very strong", only $16.8 \%$ of all Swiss students and $22.4 \%$ of Czech students share this conviction. The majority of the Swiss and Czech participants consider their influence to be unknown (15.3\% respectively $11.6 \%)$, null (14.6\% respectively $15.6 \%)$ or small (53.3\% respectively 50.3). Here we see a significant divide between East and West.

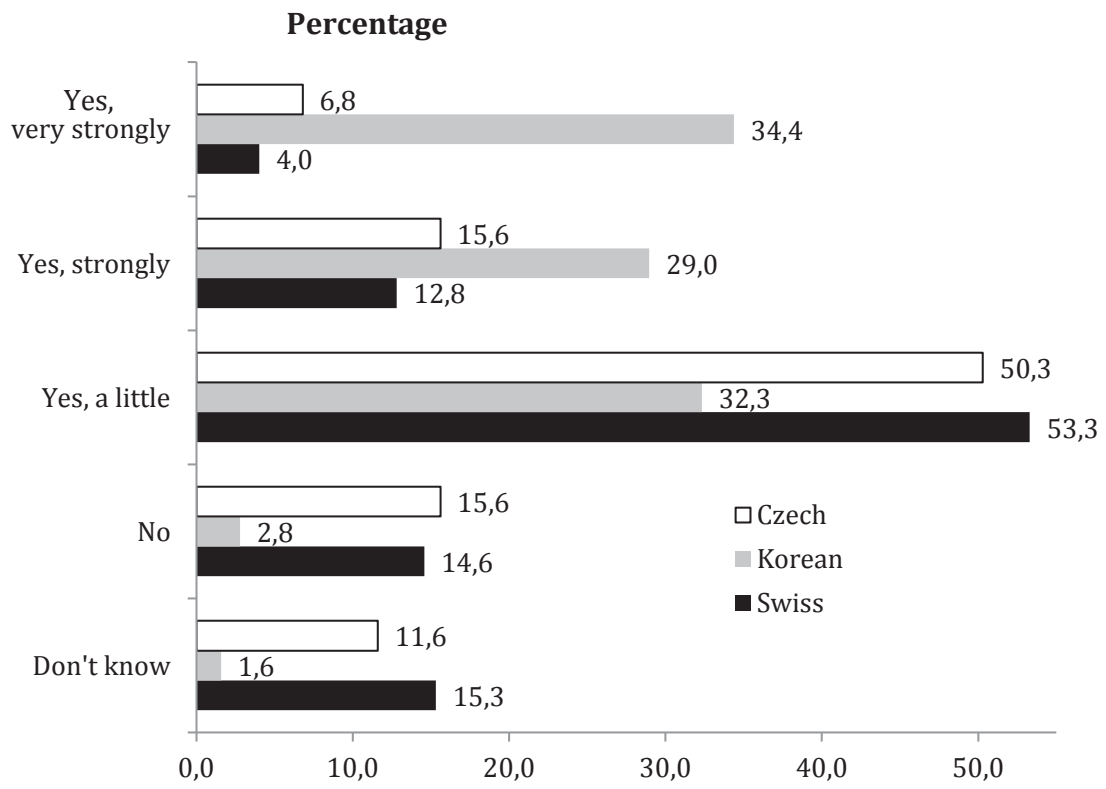

5. Nature-relatedness Self. On a scale from 1 (not at all) to 5 (very much) (3 is neutral), can you agree with the assertions listed below?

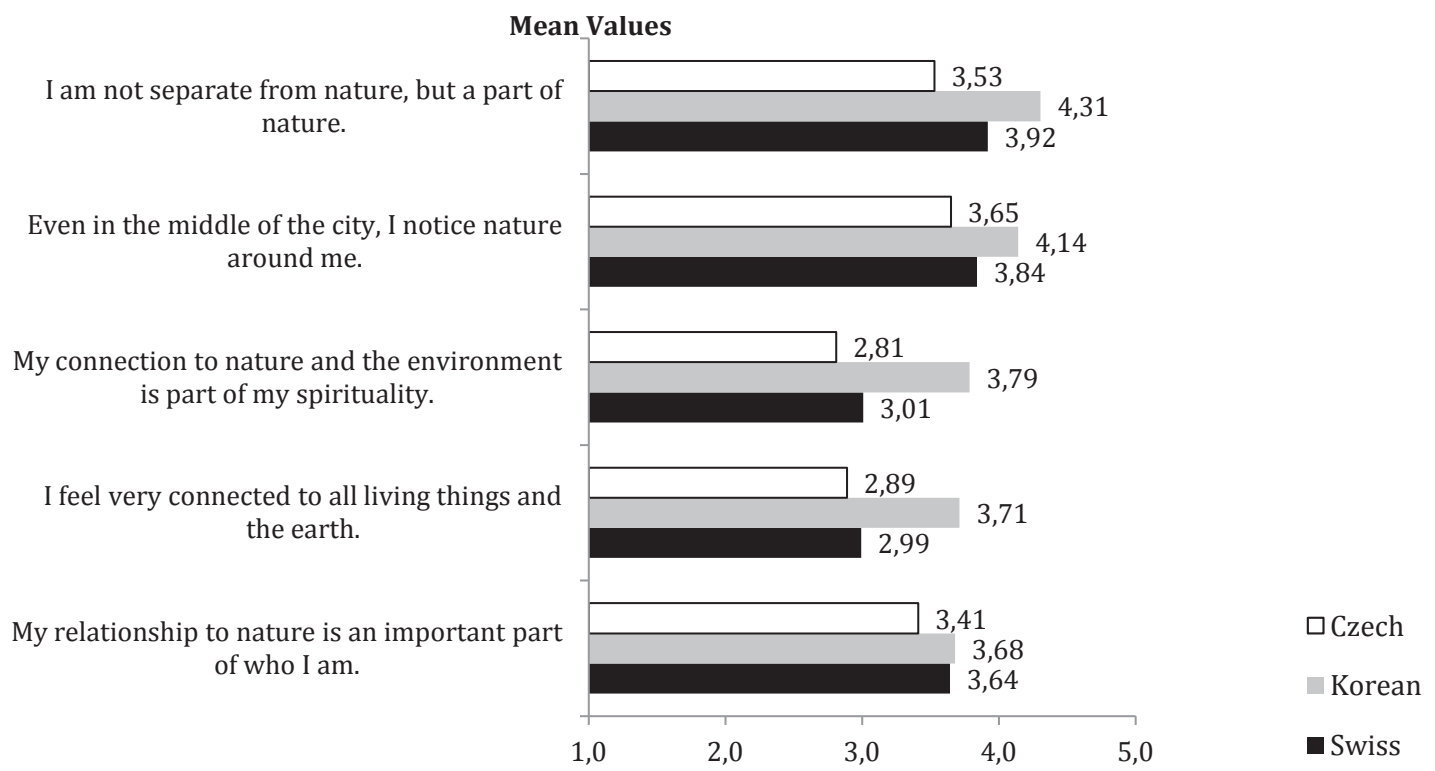

On all assertions, South Korean students reveal closer internalized identification with nature than Swiss or Czech students. Significantly diverging are the perceptions of one's separation from nature, connection to nature as part of one's spirituality, as well as one's feeling of connectedness to nature. Again on this issue, we can observe an East West divide. Between the Swiss and the Czech students there is no significant difference. However on all issues that belong to the nature-relatedness Self scale, the Czech position reveals a lower NRS. 


\section{Nature-relatedness Perspective. On a scale from 1 (not at all) to 5 (very much) ( 3 is neutral), can you agree with the} assertions listed below?

\section{Mean Values}

It would be relaxing to go hiking in the mountains far away from civilization and all by myself.

I take notice of nature wherever I am.

I often go out in nature.

I enjoy digging in the earth and getting dirt on my hands.

I enjoy being outdoors, even in unpleasant weather.

My ideal vacation spot would be a remote, wilderness area.

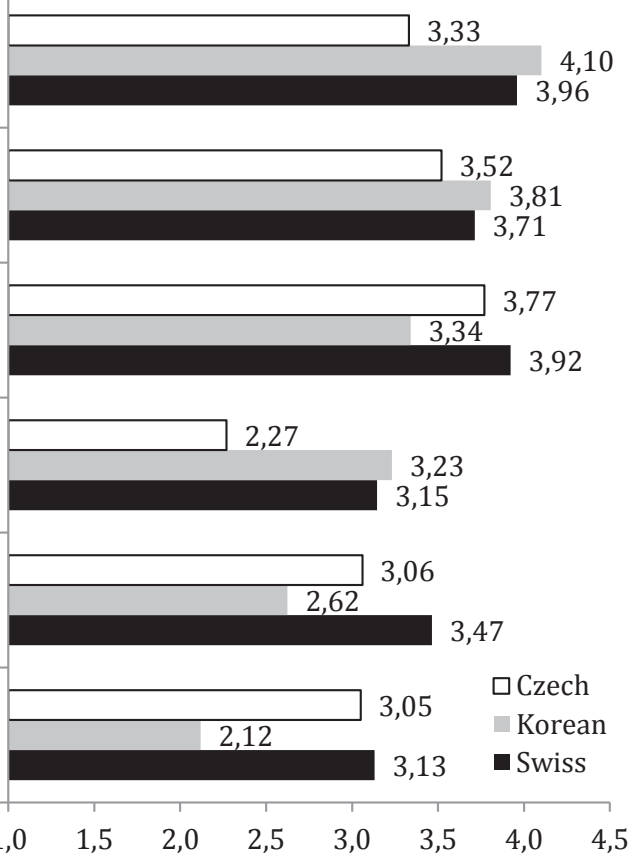

On average, South

Korean students reveal a closer nature-related worldview and a stronger sense of agency concerning individual human actions and their impact on all living things. The difference for the South Korean sample group is significantly greater on the issue of equal rights as well as the impact of one's actions in other places on the planet. On nearly all issues that belong to the naturerelatedness Perspective scale, the Czech position reveals a lower NRS.

\section{Nature-relatedness Experience. On a scale from 1 (not at all) to 5 (very much) ( 3 is neutral), can you agree with the} assertions listed below?

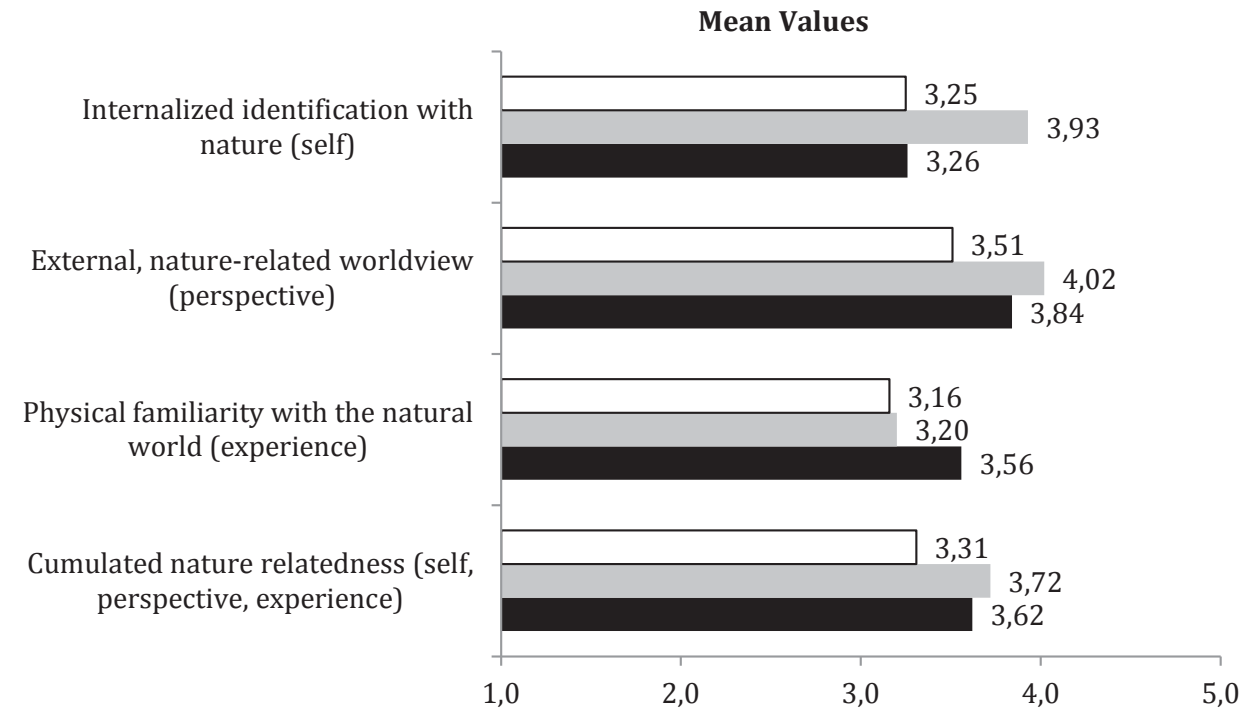

$\square$ Czech

Korean

- Swiss
On average, South Korean students reveal less physical familiarity with the natural world and a weaker desire "to be out in nature" than their Swiss and Czech counterparts. Significantly less so on the issues of often going out in nature, enjoying being outdoors, even in unpleasant weather, as well as picking a remote, wilderness area as an ideal vacation spot. There is less divergence between the Swiss and the Czech with the exception of enjoying getting dirt on one's hands. 


\section{Summary of the nature-relatedness scale questions}

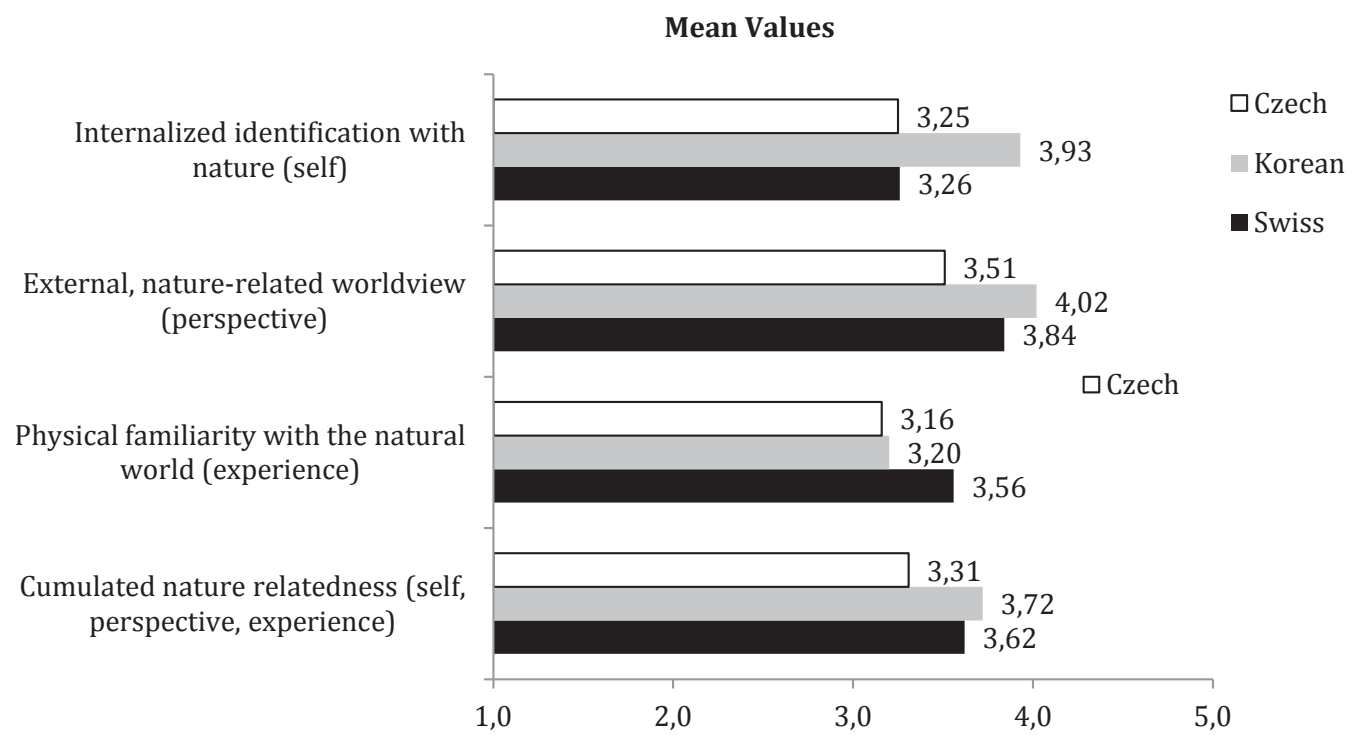

When it comes to identification (NR-Self) as well as worldview (NR-Perspective), South Korean students rank the highest. Concerning physical familiarity (NR-Experience), the Swiss students, with their more rural background, reveal the highest nature-relatedness. All in all when it comes to cumulated nature relatedness, we deduct the above presented ranking of South Korean students on the top, followed by the Swiss, and the Czechs lagging a little bit behind.

\section{Discussion}

Neither the South Korean, nor the Swiss, nor the Czech students put the perspective to live in a healthy and intact natural environment on the top of their individual agenda (question 3). Ecological considerations nevertheless influence most of their daily behavior (question 1 and 2). Regarding the future of the environment, who should take action? All three sample groups agree that self-responsibility takes priority over government or corporate responsibility (question 4). The responsibility to act lies with the individual. What is the individual's impact then? On this issue, we can identify a clear divide; the South Korean majority position reveals the following deduction: each individual should act (question $4 / 65.5 \%$ ) because every individual (or I) can make a difference (question 5 / 63.4\%). In contrast, the Swiss and Czech majority position is: each individual should act (question 4 / 59.3\% respectively 70.7\%) nevertheless each individual (or I) [alone] cannot achieve much (question $5 /$ $83.2 \%$ respectively $77.5 \%$ ). The logic behind both positions needs some clarification. Our thesis is that this difference is culture-bound.
South Korea's underlying value systems is based on Confucianism, which cherishes the concept of selfcultivation as a starting point for every societal change. The traditional East Asian approach lies in the inspiring force of the role model. Whereas in the West, societal change is ultimately brought about by normative intervention and institutional reforms, Koreans traditionally share a basic distrust of institutionally imposed laws and regulations as a reasonable means. "'A dusty book of statutes is simply too inflexible to handle the infinite variety of human experience', Master Kung said" (Reid, 2000). Instead of trusting laws, Confucius chose to trust people to rely on their intrinsic goodness and benevolent attitudes instilled by the right guidance. And by acting as a role model, the good, benevolent and virtuous person will inspire the people in his / her environment to follow his / her example. "If your desire is for good, the people will be good. (...) When the wind blows, the grass bends." (Confucius, Analects, 12/19). By acting righteously, one serves as a role model and thus one can inspire other people to more ecologically sensitive behavior. Led by one's inspiration, they will do the right thing, which will inspire other people to do the right thing, which will again inspire other people and so on. The inspirational force of the role model has no limitation. And thus the starting point of every societal change lies in the powerful inspiration and the unlimited influence of the role model.

In Switzerland, problems of the public sphere are traditionally solved by introducing new institutional frameworks / by enforcing new regulations. Due to the participatory organization of the political process 


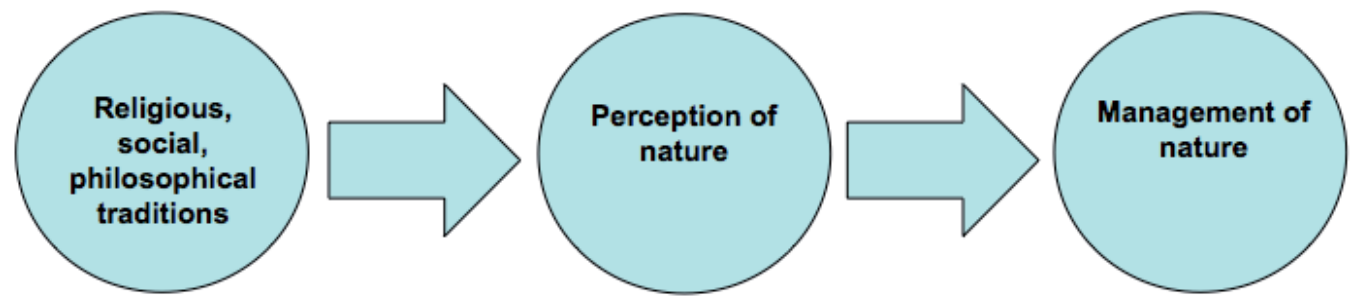

nowadays, people can directly involve themselves to initiate new laws and establish new institutions. In a direct democracy, each individual has a voice, each individual can initiate regulatory and institutional change - thus each individual should and can act (question 4) in order to initiate an institutional and regulatory change that, once established, binds every citizen. One person alone cannot achieve much (question 5). One needs to change the political framework in order to accomplish something. In contrast to the Confucian approach of role modeling, Swiss students might be more impressed by the extrinsic effect of regulatory enforcement as an adequate means to protect the environment.

In the Czech Republic, students - as individuals - are undoubtedly influenced by several factors that are philosophical, political, and socio-cultural in nature (Kohák, 2000). Similar to the Swiss, we see restraint when it comes to question five. Students doubt their individual impact in the field of ecology. It is possible that the interpretation follows the Swiss analysis presented above. We, however, consider the following thesis to be more suitable: In the Czech Republic, democratic self-confidence and civil engagement still need strengthening. The influence of the young students' parents and teachers should not be underestimated. This generation went through almost 50 years of education in the socialist spirit, where the individual did not decide anything and almost everything was decided by the leading party and the government. In this case, the Czech students' answer pattern can also be interpreted to stem from a spirit of passivity.

Is the students' concern for ecological issues related to their closeness to nature? Can we observe country specific differences on Nisbet's, Zelensky's, and Murphy's NRS? Their study (2009) with Canadian undergraduate psychology students provides evidence of a strong correlation between one's nature-relatedness and one's pleasure in spending time outdoors. "Nature-related people reported spending more time outdoors and in the natural environment. Those higher in NR [Nature relatedness scale] reported more environmental concern and endorsement of pro-environmental attitudes as well as more self-reported environmental behavior" (Nisbet, Zelensky, and
Murphy (2009), p. 733). This correlation becomes weaker in the case of South Koreans students. In this comparative survey, they - on average - reveal a higher cumulated nature relatedness scale (question 6, 7, 8) than their Swiss and Czech counterparts, but a slightly weaker scale when it comes to nature related behavior (question 8) in comparison with the Swiss.

How can this be explained? Which factors, other than the joy and habit of spending time in nature, contribute to the South Korean students' relatively strong nature relatedness? The assumption is that there is a fundamental connection between a society's management of nature and its perception of nature, which in turn is closely connected to society's inherent preeminent religious and philosophical tradition. "Religion is a powerful force in our lives because its central characteristic and function is the construction of worldviews that guide individuals and communities in decision making and action" (Colon, 2008).

Many connect traditional Western society's management of nature with its Judeo-Christian cosmology of man's mastery of nature, respectively his dominion over all life on earth (White, 1967, Callicott and Ames, 1989, Glacken, 1967, and to a certain extent Trompenaars and Hampden-Turner, 2000). Be fruitful and multiply, and fill the earth, and subdue it; and rule over the fish of the sea and over the birds of the sky and over every living thing that moves on the earth (Genesis $1 / 28$ ).

According to Bruun and Kalland (1995), the teachings of René Descartes (1596-1650), the so-called father of Modern European philosophy and science, also constitute one of the main drivers of Western perception and thus management of nature. In Descartes' words, humans should see themselves as "masters and possessors of nature" (Discourse on the Method, 1637). By standing dualistically outside a clock like world and by learning the laws of physics, humans, according to Descartes, are in the position to manipulate nature towards their own ends. From his most influential description of a mechanical and man-subordinated universe, one might deduce society's indifference towards the unprecedented destruction of nature as a concomitant phenomenon to the Industrial Revolution starting in the 18th century (Cf. Schüz, 1986, 1999a) 
Much has changed since. Having observed the detrimental changes humans have brought to their natural habitat, Western societies started to study the mechanism of environmental destruction and the limitations of humans' mastery and command over nature - this reached a large scale by the latter half of the $20^{\text {th }}$ century. Many interpreted this new paradigm shift towards an increased ecological consciousness as the "outstanding discovery of the twentieth century" (Sessions, 1987). Some even interpreted it as "the most all-encompassing revolution in the history of mankind" (Miller, 1972).

"It is not true that conversation is unnecessary because nature is strong enough to recover from any human impact." / "Humans don't have the right to use natural resources any way we want" (question 7). On the individual level, Swiss students on average very much agree with both assertions. They seemed to have internalized the general paradigm shift described above.

In contrast to the Cartesian worldview, the traditional East Asian ecological paradigm supports the concept of mankind's interconnectedness with nature. The Confucian "eco-ethics" (Yao 2000) understands humans and their natural environment to be a cooperative relationship and emphasizes the state of harmony between humans and nature. In the same way, Daoist cosmology connect mankind to nature by the principle of $G i$ (in Chinese: $Q i$ 氣) that can literally be translated as air, steam, and breath. Figuratively $G i$, however, carries the meaning of energy, vital power. Gi penetrates and accompanies all things in the universe. All things in heaven and earth are united in this one big energy flow. The same $G i$ also runs through every existing thing, which supports the existence of all other things by passing on its $G i$. (Thus the $G i$ of the sun makes the plants grow, the $G i$ of the earth carries the house, the $G i$ of the liver supports blood circulation, the $G i$ of a mother nurtures the child and so on.)

The Buddhist concept of Karma and karmic consequences also emphasizes mankind's embeddedness in nature. Buddhism sees one's life as a human as only transitory. Being human, being this individual person right now, constitutes just one stage on one's long journey through all different kinds of biological structures. Birth - life - death - rebirth / reincarnation - after myriads of years and myriads of life forms the cyclical process ends in the attainment of Nirvana, the end of all suffering. The belief that one's existence goes beyond the present human form and extends to all life forms, has traditionally created an intuitive closeness to all living things on earth.
"I am not separate from nature, but a part of nature." / "My connection to nature and the environment is part of my spirituality." / "I feel connected to all living things and the earth" (question 6). These questions might sound a little odd to Swiss students. Not so for South Korean students who grew up within the framework of the above-described "religious environmentalist paradigm" (Pedersen, 1995). The high internal consistency of the answers given on question 6 (good Cronbach $\alpha$ value of 0.823 ) supports this assumption.

But does a close identification with nature necessarily translate into environmentally sensitive behavior? Also in the East - much has changed. In their recent past, East Asian societies in general and South Korea in particular, have obviously not served as beacons of ecological sensitivity. South Korea is not unacquainted with the phenomenon of environmental disaster. By the end of the Korean War in 1953, South Korea, like many other East Asian countries, had chosen the path of rapid economic development. Technology transfer, industrialization, urbanization, rural depopulation, and environmental damage have marked South Korea's industrialization process since the early 1960 s until recently. Large-scale urbanization, industrialization, and materialism have changed South Korean management of nature such that protection and conservation of nature have become practically irrelevant in South Korea's headlong rush towards economic prosperity.

Asian cosmologies and religions seemed to have had little effect in preventing the process of urban sprawl, massive deforestation and air and water pollution. In combination with the traditional more contemplative and passive attitude towards nature's own uncontrollable course, very little has been done to soften the environmental blows of rapid industrialization. In this sense, one might even conclude that the traditional unquestionable trust in the mighty TAO and the belief in nature's self-curative power served as an accelerator of environmental degradation.

In recent times, however, in line with the global emphasis on sustainable development, South Korea has made a 180 degree turn in order to become one of the leading nations in sustainable technology development and "green-powered" growth. (See for example President Lee Myung-Bak's stimulus program in the field of research and development of alternative and renewable energy technology and other environmentfriendly projects. WEF, 2009.)

It is not true that conversation is unnecessary because nature is strong enough to recover from any human impact." / "Humans don't have the right to use natural resources any way we want" (question 7). In line with 
other previous studies (see for example OECD, 2007), this survey has shown that the focus of South Korea's younger generation does not correspond with the older generation's economic miracle-era paradigm of unlimited economic growth at any price. At the individual level, South Korean students on average very much agree with both assertions. Like their Swiss and Czech counterparts they seemed to have internalized the recent global environmental paradigm shift described above.

Today, Czech students are thinking similarly to their Swiss and South Korean counterparts. The reason they fall back a bit when it comes to their nature relatedness (see chart 9) can be explained by the general trend among post-socialist countries to lay a strong emphasis on economics and economic growth; most other issues, such as social or environmental issues, are secondary. Official political parties are engaged in the ecological questions just „by coercion“. Various scandals and political stalemates in the field of environmental restoration of polluted areas and solar energy have set a signal (Klaus, 2007). The real everyday experience of Czech students relating to missing ecological steps of government is a strong brake for some known positive approaches among the students to the environment.

\section{Impact on Business}

The surveys have shown that young people have a deep sense of nature and are willing to protect it. This has considerable consequences for business. Young consumers, by conviction, seek to cause as little damage as possible when consuming. However, thanks to a lack of understanding, or, in some cases, even pure ignorance, they are often unaware of the impact their behavior has on nature. Due to better education and information through NGOs, media, and schools they will develop a Lifestyle of Health and Sustainability (LOHAS), which, eventually translates into punishment, by virtue of boycott or non-consumption, of companies destroying nature, and award for those protecting it (cf. Greenbiz Staff, 2007, cf. Crawford, 2005). Respecting such demands poses significant challenges for companies in terms of placing their products in the market, and acquiring new young employees as well as winning their loyalty.

The corporate world cannot afford to neglect the value systems of their employees, customers and suppliers. When stakeholders want environmentally friendly technologies, companies have to fulfill these demands. It is impossible, over the long-term, to ignore them just because of profit maximization. When nature is visibly damaged, as seen in Fukushima, through corporate misbehavior, entire business segments can lose their trust-worthiness globally and they might be swept out of the market.

How can companies avoid consumer boycotts and stakeholders' loss of trust and confidence? First, they should create an authentic and credible corporate culture, based on an environmentally friendly value system that requires all employees to respond to nature's needs. Such a culture fosters the implementation of a holistic corporate responsibility system (cf. Schüz, 2012). Furthermore, they should implement socially and ecologically friendly production processes within their whole supply chain. They might follow the ideal of "cradle to cradle" which avoids waste as much as possible by cycling all side-products as a valuable resource for other production processes, similar to the cycles of life in nature (Braungart, 2002). Finally, they should compensate all self-inflicted damages to nature by re-naturalizing them whenever they can. Most of their stakeholders will reward such responsible activities for outstanding "corporate citizenship", which will lead to lowered transaction costs. All these measures express the companies' closeness to nature - a key requirement for long-term survival and "corporate health" (Schüz 1999b, 116ff). Even social systems can only survive if their members biologically survive and that - in the long run - is only guaranteed by a healthy nature.

\section{Conclusion}

In applying the NRS to South Korean, Swiss, and Czech students, this study has shown that there is an apparent personal sense of closeness to nature among the welleducated youth of today. There is a deep insight among South Korean, Swiss, and Czech students that a linear continuation of the materialistic, energy and resource intensive and narrowly self-concerned trends will lead to further environmental degradation and thus eventually endanger the existence of human civilization. A great majority of them agree that they themselves are the main agent of change. Self-responsibility takes priority over government or corporate responsibility.

How do this apparent knowledge and concern for environmental issues lead to more pro-environmental behavior? To promote environmentally responsible behavior efficiently we would like to emphasize that one has to take the cultural difference into consideration. We suggest a culture specific approach along the East (South Korean) and West (Swiss and Czech) cultural divide. For South Korea, this might mean putting a greater focus on education and role modeling whereas for Switzerland and the Czech Republic, pro-environmental change can be brought by institutional and regulatory change. 
All in all, however, the apparent recognition of the ecological limits of our planet, the recognized self-responsibility as the main agent for change, and the students' either spiritual (South Korean) or experienced (Swiss) closeness to nature give hope for a strong drive in the ongoing global ecological paradigm change. Czech students have also started to think not only about the present but also about the future of our living environment, for which they have to overtake active responsibility. It remains to be seen whether this trend among the present-day young and well-educated will translate into action in the near future when they themselves will represent the decisionmaking elite and influence corporate behavior towards a holistic and sustainable responsibility.

\section{References}

Allen, J. B., Ferrand, J. L. (1999). Environmental locus of control, sympathy, and proenvironmental behavior: A test of Geller's actively caring hypothesis.

Environment and Behavior, 31, 338-353.

Braungart, M., McDonough, W. (2002). Cradle to CradleRemaking the Way We Make Things. New York: North Point Press.

Bruun, O., Kalland, A. (1995). Asian Perceptions of Nature. A Critical Approach. London: Curzon Press.

Callicott, J.B., Ames, R. T. (1985). The Asian Tradition as a Conceptual Resource for Environmental Philosophy. Albany, NY: State University of New York.

Clayton, S. (2003). Environmental identity: A conceptual and operational definition, in Identity and the natural environment: The psychological significance of nature, ed. Clayton,S., Opotow, C., Cambridge, MA: MIT Press, 45-65.

Colon, R. L. (2008). Religious Groups and Climate Change. Drivers, Barriers and Religious Engagement on Climate Change. Lund: IIIEE Publications.

Conn, S. A. (1998). Living in the earth: Ecopsychology, health and psychotherapy. The Humanistic Psychologist, 26 (1-3), 179-198.

Crawford, D. (2005). The Balanced Scorecard and Corporate Social Responsibility: Aligning Values for Profit, (accessed September 25, 2012), [available at http://www.greenbiz. com/news/2005/10/23/balanced-scorecard-and-corporatesocial-responsibility-aligning-values-profit] .

Descartes, R. (2008). Discourse on the Method and Meditations on First Philosophy. New Haven: Yale University Press.

Dunlap, R. E., VanLiere, K. D. (1978). The new environmental paradigm: A proposed measuring instrument and preliminary results. The Journal of Environmental Education, 9, 10-19.

Dunlap, R. E., Mertig, A. G. (1995). Global concern for the environment: Is affluence a prerequisite? Journal of Social Issues, 51, 121-137.

Dunlap, R. E., Van Liere, K. D., Mertig, A. G., Jones, R. E. (2000). Measuring endorsement of the new ecological paradigm: A revised NEP scale. Journal of Social Issues, $56,425-442$.
Dutcher, D. D., Finley, J.C., Luloff, A.E., Buttolph Johnson, J. (2007). Connectivity with nature as a measure of environmental values. Environment \& Behavior, 39, 474-493.

Frantz, C.M., Mayer, F.S. (2009). The emergency of climate change: Why are we failing to take action? Analyses of Social Issues and Public Policy, 9, 205-222.

Glacken, C. J. (1967). Traces on the Rhodian Shore. Nature and Culture in Western Thought from Ancient Times to the End of the Eighteenth Century. Berkley: University of California Press.

Greenbiz Staff (2007). LOHAS Forum Sees Big Growth in Green Marketplace, (accessed May 23, 2012), [available at „http://www.greenbiz.com/news/2007/05/29/ lohas-forum-sees-big-growth-green-marketplace“

Howard, G. S. (1997). Ecological psychology: Creating a more earth-friendly human nature. Notre Dame, IN: University of Notre Dame Press.

Iwata, O. (2001). Relationships between proenvironmental attitudes and concepts of nature. The Journal of Social Psychology, 14, 75-83.

Kaiser, F. G., Wölfing, S., Fuhrer, U. (1999). Environmental attitude and ecological behavior. Journal of Environmental Psychology, 19, 1-19.

Kals, E., Schumacher, D., Montada, L. (1999). Emotional affinity toward nature as a motivational basis to protect nature. Environment and Behavior, 31, 178-202.

Kaplan, S. (2000). Human nature and environmentally responsible Behavior. Journal of Social Issues, 56, 491-508.

Kellert, S. R, Wilson, E. O. (1993). The biophilia hypothesis. Washington, DC: Island Press.

Klaus, V. (2007). Modrá, nikoli zelená planeta. Co je ohroženo: klima, nebo svoboda? Prague: Dokořán.

Kohak, E. (2006). Zelená svatozár̆, Kapitoly z ekologické etiky. Prague: Sociologické nakladatelství.

Kortenkamp, K. V., Moore, C. F. (2001). Ecocentrism and anthropocentrism: Moral reasoning about ecological commons dilemmas. Journal of Environmental Psychology, 21, 261-272.

Laszlo, E. (2008). Quantum Shift in the Global Brain-How the New Scientific Reality Can Change Us and Our World. Rochester, VT: Inner Traditions.

Mayer, F. S., Frantz, C. M. (2004). The connectedness of nature scale: A measure of individuals' feeling in community with nature. Journal of Environmental Psychology, 24, 503-515.

Mayer, F. S., Frantz, C. M., Bruehlman-Senecal, E., Dolliver, K. (2009). Why is nature beneficial? The role of connectedness to nature. Environment \& Behavior, 41, 607-643.

Miller, G. T. (1972). Replenish the Earth: A Primer in Human Ecology. Florence, KY: Wadsworth Publishing Co Inc.

Mitchell, S. (1999). Lao Tzu. Tao Te Ching. London: Frances Lincoln Ltd.

Naess, A. (1973). The shallow and the deep ecology movements. Inquiry, 16, 95-100.

Nisbet, E. K., Zelenski, J. M., Murphy, S. A. (2009). The Nature Relatedness Scale: linking individuals' connection with nature to environmental concern and behavior. Environment \& Behavior, 41, 715-740. 
Nisbet, E. K., Zelenski, J. M., Murphy, S. A. (2011). Happiness is in our nature. Exploring nature relatedness as a contributor to subjective well-being. Journal of Happiness Studies, 13, 303-322.

Nordlund, A. M., Garvill, J. (2002). Value structures behind proenviromental behavior. Environment and Behavior, 34, 740-756.

OECD. Programme for International Student Assessment (2009). Green at Fifteen? How 15-Year-Olds Perform in Environmental Science and Geoscience in Pisa 2006. Paris: OECD.

Pedersen, P. (1995). Nature, Religion, and Cultural Identity: The Religious Environmentalist Paradigm, in Asian Perceptions of Nature: A Critical Approach, ed. Bruun, O., Kalland, A., London: Curzon Press, 258-276.

Pelletier, L. G., Dion, S., Tuson, K., Green-Demers, I. (1999). Why do people fail to adopt environmental protective behavior? Toward a taxonomy of environmental amotivation. Journal of Applied Social Psychology, 29, 2481-2504.

Pooley, J. A., O'Connor, M. (2000). Environmental education and attitudes: Emotions and beliefs are what is needed. Environment and Behavior, 32, 711-723.

Rantanen, J. (2009). Reconnecting with Nature and Pro-Environmental Consciousness and Behavior. Lund: IIIEE publications.

Reid, T. R. (2000). Confucius lives next door. What living the East teaches us about living in the West. New York: Random House.

Schüz, M. (1986). Die Einheit des Wirklichen - Carl Friedrich v. Weizsäckers Denkweg. Pfullingen: Neske Verlag.

Schüz, M. (1999a). Die Einheit des Wirklichen - Denken und Handeln im Spannungsfeld von Physik und Religion, in Der Schöpfung auf der Spur - Theologie und Naturwissenschaft im Gespräch, ed. Audretsch, J., Nagorni, K., Karlsruhe, 9-33.

Schüz, M. (1999b). Werte - Risiko - Verantwortung. Dimensionen des Value Managements. München: Gerling Akademie Verlag.

Schüz, M. (2012). Sustainable Corporate Responsibility - The Foundation of Successful Business in the New Millennium”, in: Central European Business Review, 1 (2), 7-15.

Sessions, G. (1987). Deep Ecology Movement. A Review. Environmental Review, 11 (2), 105-125.

Stern, P. C., Dietz, T. (1994). The value basis of environmental concern. Journal of Social Issues, 50 (3), 65-84.

Trompenaars, F., Hampden-Turner, C. (2000). Building Cross-Culture Competence. How to Create Wealth from Conflicting Values. Newhaven: Yale University Press.

White, L. (1973). The Historical Roots of Our Ecological Crisis, in Western Man and Environmental Ethics, ed. Barbour, I.G., Reading, Mass.: Addison Wesley.

Wilson, E. O. (1984). Biophilia. Cambridge, Mass.: Harvard University Press.
World Economic Forum on East Asia (2009). Implications of the Global Economic Crisis for East Asia. Report on the WEF in Seoul, 18.-19. June 2009.

Yao Xinzhong (2000). An Introduction to Confucianism. Cambridge: Cambridge University Press.

\section{Authors}

Petra Y. Barthelmess

Lecturer for Business Administration, Center for International Business Zurich University of Applied Sciences (ZHAW) School of Management and Law Stadthausstrasse 14 $\mathrm{CH}-8401$ Winterthur petra.barthelmess@zhaw.ch

Mathias Schüz

Deputy Head of Center for International Business School of Management and Law Zurich University of Applied Sciences (ZHAW) Stadthausstrasse 14 $\mathrm{CH}-8400$ Winterthur mathias.schuez@zhaw.ch

Rainer Fuchs

School of Management and Law Zurich University of Applied Sciences (ZHAW) Stadthausstrasse 14 $\mathrm{CH}-8400$ Winterthur rainer.fuchs@zhaw.ch

Dušan Kučera

International School of Business and Management Faculty of Business Administration University of Economic, Prague Nám. W. Churchilla, 4, 13067 Praha 3 dusan.kucera@vse.cz

\section{Markus Prandini}

Head of the Center for International Business School of Management and Law at Zurich University of Applied Sciences Stadthausstrasse 14, CH-8401 Winterthur markus.prandini@zhaw.ch 